\title{
O PAPEL DA EDUCAÇÃO NA APRENDIZAGEM E NO CONHECIMENTO
}

Vera Rudge Werneck ${ }^{(*)}$

\section{INTRODUÇÃO}

O tema "o papel da educação na construção do conhecimento" é bastante instigante e de grande interesse para educadores em geral.

A noção de educação é extremamente ampla e como termo análogo, permite interpretações semelhantes, mas não idênticas que levam a práticas diversas. Diante do desafio de refletir sobre essa questão, inicia-se pela análise da compreensão de "educação" e pelas consequências de suas diferentes interpretações.

Outro item a ser discutido é o significado do termo "construção" ligado ao conhecimento. Inúmeros autores referem-se ao termo com diferentes interpretações. Em que sentido é ele empregado ao referir-se ao conhecimento?

Finalmente vai ser preciso refletir sobre a noção de conhecimento relacionado com o processo de aprendizagem. Como se chegar ao conhecimento?

Percebe-se, atualmente, um constante desejo de mudança. Talvez sob o impacto do progresso da moderna tecnologia, o novo, a novidade, apresenta-se como sinônimo de bom. O conhecimento pelo conhecimento não faz sentido. A aprendizagem se justifica quando aperfeiçoa o sujeito, quando o faz melhor. Quando aprimora sua saúde, seu bem estar, sua capacidade crítica, sua ação responsável, seu convívio social na vivência de cidadania.

O grande desenvolvimento da tecnologia da comunicação levou a interpretações discutíveis como a que entende "conhecimento" como domínio da tecnologia, como possibilidade de informação rápida.

Nem a tradição nem a inovação podem ser entendidas como valores absolutos. Consideradas em si mesmas, pouco significam. A tradição pela tradição pode resultar no imobilismo, na cristalização, nos rituais vazios de sentido. Práticas tradicionais só devem ser conservadas se representarem valores para o sujeito. Do mesmo modo, a novidade, a inovação por ela mesma de

\footnotetext{
${ }^{(*)}$ Doutorado em Filos ofia pela Universidade Gama Filho (1988), mestrado em Filosofia pela Pontifícia Universidade Católica do Rio de Janeiro (1963) e possui graduação em Filosofia pela Pontifícia Universidade Católica do Rio de Janeiro (1959). Atualmente é profess or titular da Universidade Católica de Petrópolis .
} 
nada vale podendo levar ao modismo, à inconstância, à falta de estabilidade e de continuidade, à imprevisibilidade.

Muito se discute sobre a escola ideal do século XXI em um mundo tão dependente das novas tecnologias. A afirmação de que o aluno de hoje empoderado pela tecnologia deveria ser instigado a solucionar os problemas do mundo real não leva em conta o seu desenvolvimento intelectual e emocional. A facilidade da informação não significa maior nível de educação. Somente ela não habilita ninguém a resolver as dificuldades da atualidade. Novas práticas didáticas, novos recursos para o ensino são sempre bem vindos, mas por si só não são suficientes para promoverem a educação. O objetivo do ensino não é apenas a transmissão do já conhecido, mas o desenvolvimento da capacidade de observação e de reflexão crítica. Os métodos podem evoluir, podem ser aprimorados para melhor satisfazerem aos anseios do sujeito, mas sendo ele um ser social, a transmissão da bagagem de conteúdos de uma geração à outra deve vir sempre ligada à busca de sentido.

As instituições de ensino formal ao ensinarem a pensar, a analisar, a criticar, a sintetizar estão cumprindo a sua missão de promover o aperfeiçoamento humano, o aprimoramento da sociedade e a preparação do estudante para a produção do conhecimento.

\section{O PAPEL DA EDUCAÇÃO: A NOÇÃO DE EDUCAÇÃO}

Inúmeras são as conceituações de educação. Não cabe aqui enumerá-las nem analisa-las separadamente. Desde as que se fundamentam na etimologia até às mais livres e políticas. Vai-se apenas dar ênfase à que serviu de referência para essa reflexão: "educação é o processo que leva o educando a reconhecer, buscar, instaurar e hierarquizar os valores de modo a aprimorar-se como 'pessoa' e como 'personalidade'.'.

A noção de educação vincula-se ao reconhecimento do valor e à assimilação do que vale para a vida do homem, para o seu bem estar e bem viver. Pelo exercício da sensibilidade vai detectar e apreender o valor como o que pode promover a construção do sujeito.

Entendida como processo de aperfeiçoamento e de humanização do sujeito, a educação foi sempre considera como fundamental e necessária.

O produto da educação é o educado, ou seja, aquele que se desenvolveu como "pessoa" aprimorando a sua corporeidade cuidando da sua saúde e do seu bem estar físico, da sua racionalidade buscando o conhecimento e a sua capacidade de análise crítica. Da sua vontade 
exercendo a sua liberdade psicológica e a sua responsabilidade e, por fim, sua afetividade pelo aperfeiçoamento da sua capacidade de amar, de doar-se, de participar da vida social.

"Pessoa" seria o indivíduo racional, capaz de liberdade psicológica e de vida afetiva. O "educado", além de aprimorar-se como "pessoa" o faz também como "personalidade" individual com características próprias e peculiares. Também o desenvolvimento da "personalidade" própria de cada um, deve ser objetivo do processo da educação.

\section{A NOÇÃO DE INSTRUÇÃO}

Frequentemente se confundem as noções de educação e de instrução que são tomadas como sinônimas ou pelo menos, com significados semelhantes. Há, evidentemente, uma inter-relação e mesmo uma interação entre elas, mas, seus significados são distintos e devem ser explicitados para a validade de qualquer reflexão científica.

A educação é confundida com a instrução quando entendida como conhecimento intelectual, como domínio da ciência e da tecnologia ou mesmo com a escolarização. Nesse sentido, o educado seria o capaz de ler, de escrever, de dominar as operações da matemática. $\mathrm{O}$ mais educado seria o que tivesse maior número e os mais elevados títulos acadêmicos.

A instrução visa o conhecimento do real, ou seja, a "verdade". A verdade é um valor por corresponder ao anseio humano de conhecer o real como é. Apesar desse conhecimento nunca ocorrer de modo perfeito, a necessidade, o anseio por esse valor revela-se como próprio do homem que não se satisfaz com o erro e com a mentira.

O instruído é tido como educado por ter conhecimentos e, por isso, condições para viver e produzir de um modo útil para si próprio e para a sociedade. Choca, no entanto o fato, aparentemente inexplicável de encontrarem-se pessoas instruídas e não educadas por não reconhecerem os valores e não os hierarquizarem adequadamente.

Tem conhecimento quem é capaz de distinguir o essencial do acidental, é capaz de ordenar e hierarquizar o conteúdo apreendido, de situar no tempo e no espaço, de delimitar causas e consequências.

O conhecimento resulta da construção do sentido a partir de uma aquisição de informações: uma leitura, uma aula, uma palestra, um filme, da mídia enfim. Não se aceita, no entanto, a construção de qualquer sentido, mas somente daquele adequado. Não há propriamente, uma completa liberdade nessa construção, pois ela deve constituir um processo de aprendizagem, de 
incorporação de um conteúdo que respeite determinados protocolos para que fique garantida a comunicação entre os que dominam o mesmo conhecimento e detêm o mesmo grau de instrução.

De modo geral, a instrução é adquirida nas instituições de ensino; A escola de ensino Fundamental e Médio vai disponibilizar ao aluno o conhecimento científico atualizado. Propiciar ao estudante o contato com os conhecimentos relativos à natureza, à vida social, ou seja, com toda a produção científica do momento e, ao mesmo tempo, inicia-lo na metodologia científica preparando-o para a pesquisa.

Os conteúdos dos conhecimentos transmitidos pela escola apresentam características próprias por resultarem da recontextualização do discurso científico para que se adapte ao nível de desenvolvimento do aluno. É o que entende por transposição didática.

Cabe à escola a constante atualização de suas disciplinas e a avaliação continuada de seus processos de ensino para proteger-se da interferência do imaginário social e da parcialidade de sua atuação.

\section{A NOÇÃO DE CULTURA}

Basicamente são duas as conceituações de culturas: primeiramente a que a entende como qualquer produção humana, qualquer interferência sua na natureza em geral, no outro ou em si próprio. Seria considerado como cultura tudo o que resultasse do agir humano englobando o valor e o contravalor o que levaria a grandes impasses no plano da Educação, da Ética e do Direito.

Para a segunda conceituação, o fenômeno da cultura é constituído apenas pela produção humana que agregue algum valor ao meio ambiente físico ou social, ao outro ou a si mesmo.

Frequentemente, confunde-se educação e cultura, quando se considera como "educado" e que participa da cultura do seu tempo e do seu espaço por conhecer e utilizar a bagagem que a constitui. Aquele que domina a produção cultural, artística, científica e tecnológica da sua geração. Registram-se, no entanto, alguns obstáculos a esse entendimento: a interferência do fator econômico e das condições existenciais de cada um que tornam possível a existência do aculturado e não educado. Obrigatoriamente, o indivíduo que por boas condições econômicas tivesse acesso a toda a produção cultural do seu tempo não poderia ser, só por essa circunstância, considerado como "educado", mas somente como adaptado à vida da sua comunidade. 
Entendendo-se a cultura como o resultado, o produto da ação humana mobilizada pela sensibilidade e pela razão, ou seja, pela educação e pela instrução, estaria sempre em evolução sendo passível de crítica e de aprimoramento. A cultura não é algo pronto, acabado que deve ser passivamente aceito e transmitido às novas gerações, mas uma bagagem que está sempre em transformação em processo de aprimoramento. A educação não pretende uma imposição arbitrária que garanta a reprodução do modo de ser da sociedade, mas sim a sua transformação para a sua humanização.

A produção cultural pode ser proveniente diretamente do imaginário como no folclore, da sensibilidade como na obra de arte ou do conhecimento racional como na ciência, e na tecnologia. Há certamente a combinação dessas fontes: imaginário, sensibilidade, razão na construção da cultura. Os fatores interagem para a produção dos bens culturais. São bens culturais: as cantigas de roda, as danças, as obras clássicas de música, de pintura, de escultura, as leis, os códigos, as obras urbanísticas, os medicamentos, a produção tecnológica. Todos resultantes da ação humana sobre a natureza.

Também a construção do próprio sujeito é considerada como cultura. Ele torna-se mais aculturado quando participar do "modus vivendi" de seu meio social e culto ao assimilar os saberes academicamente constituídos.

Miguel Reale (1996, p. 19) entende a cultura como a "universalidade dos bens espirituais subjetivos e objetivos que a humanidade vem construindo ao longo do tempo tendo em vista a realização de seus fins próprios.” Nessa conceituação ficam eliminadas da cultura as produções que não representam "bens" para o homem e subentendida a existência de fins próprios e impróprios para sua realização.

\section{Para Muniz Sodré,}

Cultura é o conjunto dos instrumentos de que dispõe a mediação simbólica (língua, leis, ciência, artes, mitos) para permitir ao indivíduo ou ao grupo a abordagem do real. Os instrumentos ditos culturais são "equipamentos" coletivos ou grupais postos à disposição de todos. (SODRÉ, 2001, p. 85).

O educar é ainda confundido com o civilizar: Civilizado seria o que participasse do desenvolvimento tecnológico de sua geração enquanto que o aculturado o que conhecesse os padrões culturais de seu tempo por um esforço pessoal de aprimoramento.

Chega-se a que "a educação não tem por objetivo apenas a reprodução da cultura, a transmissão de ideias, sentimentos, hábitos e técnicas da coletividade o que levaria a um 
relativismo, representando um reducionismo de sua dimensão.” (WERNECK, 2003, p. 75) O processo da educação não se limita ao de adaptação, a padrões culturais vigentes. Ele se propõe a uma transformação, à humanização da cultura.

A clássica afirmação de cabe à educação "formar" o indivíduo, de dar-lhe forma segundo um modelo, um ideal previamente estabelecido só pode ser aceita não como algo pronto e predeterminado, mas como a capacidade de construir-se, de construir o próprio conhecimento pelo domínio das condições exigidas para tal.

Por vezes, identifica-se o educado como aquele que participa do mundo da cultura do seu tempo. Aquele que participa de determinadas produções culturais consideradas universalmente válidas: domínio das ciências, letras e artes entendidas como "superiores" pelos intelectuais. Uma noção sempre associada a conhecimento escolar. Educado seria o mais capaz de conhecer as diversas áreas do real e assim, ter poder sobre elas. De outro ponto de vista, cabe à educação dar os meios para que cada um possa decidir sobre sua vida.

\section{A EDUCAÇÃO FORMAL, NÃO FORMAL E INFORMAL}

Como consideração final dessa primeira parte de reflexão sobre a questão da educação vaise registrar que ela não advém apenas da instituição escolar, mas ainda de cursos e programas independentes e do próprio meio familiar e social. Pode-se assim, como afirmam Ghanem e Trilla reconhecer uma educação formal, uma não formal e a informal. Afirmam eles: "Provavelmente, foi devido a considerações desse tipo que, poucos anos depois da obra, digamos institucional, o próprio Coombs (1968 apud TRILLA; GHANEM, 2008) e seus colaboradores propuseram a distinção entre três tipos de educação: a formal, a não formal e a informal." E continuam: "a educação formal compreenderia 'o sistema educacional' altamente institucionalizado, cronologicamente graduado e hierarquicamente estruturado que vai dos primeiros anos da escola até os últimos da universidade", a educação não formal, 'toda atividade organizada, sistemática, educativa, realizada fora do marco do sistema oficial, para facilitar determinados tipos de aprendizagem a subgrupos específicos da população tanto adultos como infantis" e a educação informal "um processo que dura a vida inteira, em que as pessoas adquirem e acumulam conhecimentos, habilidades, atitudes e modos de discernimento por meio de experiências diárias e sua relação com o meio.” (COOMBS, 1975, p. 27)

Esses três modos de educação devem ser considerados quando se reflete sobre a interferência da educação na construção do conhecimento. 


\section{A CONSTRUÇÃO DO CONHECIMENTO: A NOÇÃO DE APRENDIZAGEM}

Uma das maiores dificuldades na questão do conhecimento decorre da imprecisão dos termos empregados. Quando se toma o tema da aprendizagem surge a noção de construção do conhecimento como explicação para o seu processo.

Aprender é um termo com um significado extremamente amplo que vai desde as aquisições motoras, aprender a andar, a coordenar os movimentos até o conhecimento científico e às reflexões filosóficas mais profundas. São inúmeras as teorias da aprendizagem desde o construtivismo de Piaget, à de Vigotski, passando por Aristóteles, São Tomás de Aquino, F. Bacon, R. Descartes e pela Fenomenologia.

De acordo com o dicionário de Houaiss (2004), aprender é "adquirir conhecimento (de) ou habilidade prática, ter melhor compreensão de algo esp. por intuição, experiência, convivência.”. Já em Caldas Aulete (2009, p.56), encontra-se: aprender: "alcançar o conhecimento, a compreensão ou o domínio por meio do estudo ou da prática.”. Adquirir habilidade de, tornar-se adestrado.

$\mathrm{Na}$ busca do saber pode-se adquirir conhecimento empiricamente, aprendendo a fazer sem uma maior compreensão do nexo causal que dá origem ao fenômeno. Seria uma aprendizagem pela experiência como nadar, dirigir um automóvel ou buscar um analgésico para uma dor.

É possível o conhecimento científico quando se aprende o nexo de causa e efeito do fenômeno e sistematiza-se esse conteúdo. Como consequência pode-se desenvolver uma tecnologia com base no conhecimento adquirido. Pode-se buscar as causas remotas dos fenômenos atingindo o nível filosófico.

Há, portanto diversas modalidades e níveis de aprendizagem e uma pluralidade de discursos científicos. Cada saber científico tem seu próprio estatuto de cientificidade.

O conhecimento empírico, ligado ao fazer, ao senso comum é bastante influenciado pelo imaginário social, marcado pelo preconceito e por interpretações ideológicas. Com o início do pensamento lógico, começa o interesse pelas relações causais de simultaneidade e de contiguidade. Pelas noções de substância e de acidente, de classificação e de ordenamento. Inicia-se a estruturação de um corpo de ideias que vai constituir o conteúdo dos diversos saberes.

A aprendizagem da ciência vai corrigir a construção do saber empírico. Sendo a ciência um novo olhar, um outro modo de ver o real, vai ser necessária uma metodologia própria para que o processo ocorra satisfatoriamente. A avaliação do nível de conhecimento é feita pela utilização 
prática que dele se faz. Em que medida no seu dia a dia o sujeito se utiliza do conhecimento aprendido.

Não se pode falar de aprendizagem sem mencionar a importância do ensino. Podem-se buscar novos métodos, procurar o seu aprimoramento, mas, sendo o homem um ser social, a transmissão da bagagem de conteúdos e da reflexão crítica de uma geração para a seguinte é inevitável e fundamental. Cabe à escola a socialização do conhecimento, ou instigação à curiosidade, a instauração do hábito do rigor metodológico, mas não propriamente a produção da ciência. O objetivo primordial das instituições de ensino seja em que nível for, não é a produção de saberes no sentido de resultados de pesquisa científica, mas a construção individual do conhecimento. Divulgar saberes existentes com reflexão crítica é o melhor modo de propiciar a produção do conhecimento. Cresce por isso, a importância do professor. Vai ser necessária a sua constante atualização, seu interesse pela disciplina, sua capacidade de interpretação do real para uma boa atuação. Importa mais desenvolver o espírito de pesquisa, despertar o aluno para a observação e a reflexão do que a pesquisa propriamente dita que exige tempo e dedicação para a sua conclusão. O docente deve buscar a excelência na docência assim como o pesquisador na pesquisa.

Admitindo-se como objetivos primordiais da Universidade, o desenvolvimento do sujeito e a divulgação do conhecimento científico, a pesquisa se justifica como um meio de ensino da ciência, como técnica didática. A Universidade é eminentemente crítica e, por isso, precisa ser livre e independente de ideologias e do poder econômico ou do Estado para que possa transmitir o conhecimento acumulado de modo que seja adequadamente construído no estudante e assim propiciar o desenvolvimento da pesquisa.

\section{A NOÇÃO DE CONSTRUÇÃO}

Entendendo-se por construção o ato de construir algo e como ato ou ação a terceira fase do processo da vontade, fica implícito que a construção do conhecimento depende da autonomia do sujeito. Embora ocorra o ato reflexo, o ato instintivo, o ato espontâneo como movimentos do sujeito que independem da sua vontade, o ato livre vai exigir a interferência desta. Pode haver um aprendizado no plano motor, aprender a andar, no plano instintivo, aprender a mamar, mas o aprendizado do conhecimento intelectual exige o concurso da vontade do sujeito. 
Como teoria, o Construtivismo vai propor uma modalidade de aquisição do conhecimento em que o sujeito de modo ativo compreenda cada fase do processo, perceba os nexos causais existentes entre eles e incorpore como seu aquele conteúdo. Não significa que deva reconstruir por si mesmo a bagagem científica já constituída.

Com Jean Piaget (2002) iniciam-se as pesquisas de psicologia genética que deram origem ao chamado "Construtivismo-Interacionismo" genético que tinha como objetivo estudar o processo de constituição do conhecimento humano. Conhecer as fases do processo é fundamental para a seleção dos conteúdos a serem oferecidos.

As inúmeras concepções filosóficas e epistemológicas apresentam diferentes teorias sobre o processo de produção do saber. Algumas características desse processo são, no entanto, universalmente aceitas nos dias atuais:

- A provisoriedade dos saberes científicos: não mais se aceita o conhecimento como um processo cumulativo. Há, na ciência, uma revisão constante decorrente da possibilidade de novos pontos de vista. O mesmo objeto pode ser analisado de diferentes ângulos o que leva não ao relativismo, mas à constatação da relatividade do conhecimento;

- A interferência do imaginário na produção do conhecimento pela via da cosmovisão e da ideologia. Entendendo-se como cosmovisão a visão de mundo do sujeito cognoscente decorrente da sua posição histórico-geográfica, cultural e econômica e a ideologia como a orientação originária do imaginário que determina os papéis e as funções sociais, percebe-se a interferência desses dois fatores na produção do conhecimento;

- A impossibilidade de neutralidade axiológica. Não sendo possível a neutralidade e a imparcialidade na constituição dos saberes há sempre a interferência dos valores aceitos pelo sujeito na produção do conhecimento.

Embora Piaget (1977, p. 17) considere ser "a inteligência um sistema de operações vivas e atuantes da natureza adaptativa" e afirme que o essencial do pensamento lógico é ser operativo com o fim da constituição de sistemas, não descarta a interferência da afetividade no processo do conhecimento. Reafirma a existência de um paralelo constante entre a vida afetiva e a vida intelectual considerando-as como dois fatores indissociáveis e complementares de toda a conduta humana. 
Tais considerações trazem, senão dificuldades, pelo menos, maior exigência de reflexão sobre a noção de "construção de conhecimento".

Refere-se ele ainda ao interesse como essencial para todo ato de assimilação mental. Interesse seria a expressão do ato de assimilação como incorporação de um objeto à atividade do sujeito, ou seja, o conhecimento só ocorreria quando o seu objeto se manifestasse na atividade do sujeito.

No seu pensar as estruturas lógicas somente se constituem quando ocorrerem ações sobre os objetos, ou seja: a fonte das operações lógicas é sempre a própria ação. Essas afirmações parecem permitir entender o seu conceito de ação como estado mental de atividade e de interesse.

$\mathrm{Na}$ sua obra "Seis estudos de Psicologia" (PIAGET, 1978, p. 15) mostra que as teorias correntes do desenvolvimento, da gênese, na psicologia da inteligência, invocam três fatores, seja um a um, seja simultaneamente:

- a maturação: um fator interno estrutural, mas hereditário;

- a influência do meio físico, da experiência ou do exercício;

- a transmissão social.

O aprendizado, a construção do conhecimento exige, portanto, um estado de atividade por parte do sujeito sem que isso signifique ausência de ensino, de transmissão social.

Aplicado à educação pode-se entender construção como:

a) saber produzido pelo filósofo, pelo cientista resultante da reflexão e da pesquisa sistemática: os conteúdos das ciências e dos diferentes saberes das diversas áreas do conhecimento humano. Conhecimento resultante da investigação filosóficocientífica.

b) construção: modo pelo qual cada um aprende a informação e aprende algum conteúdo. O sujeito não propriamente "constrói” o saber, mas o “constrói” em si mesmo, apropriando-se de um conhecimento já estabelecido. Cada sujeito apreende o que lhe foi transmitido de um modo semelhante, mas não idêntico. É a semelhança que permite a comunicação. Há, como afirma Husserl (1980) uma intersubjetividade entre os que dominam a mesma área do saber que demonstra uma identidade na construção do conhecimento. 
Essa compreensão do termo "construção" aplicado ao conhecimento, não é totalmente livre e aleatório levando ao solipsismo e à incomunicabilidade, mas vai corresponder a uma concordância, a um consenso universal. Não seria possível cada um "construir" o seu conhecimento de modo totalmente pessoal e independente. O conhecimento deve estar de acordo com a comunidade científica e com o saber universal.

O termo "construtivismo" talvez possa ser entendido como uma condenação ao processo impositivo de transmissão do conhecimento. Levanta a possibilidade de uma transmissão sem imposição e de uma recepção sem a característica da passividade.

Dessa colocação, chega-se à admissão de uma maneira "certa", "correta", "adequada" de conhecer que não é a da passividade, a da aceitação tácita, a de decorar fórmulas prontas, mas a do sujeito ativo que compreende os conteúdos, que refaz os passos do processo, que procura entender os significados e os sentidos como que a "reconstruir" por si próprio o conhecimento.

O sujeito não vai refazer o caminho da ciência, "redescobrir", "reinventar" os conteúdos dos saberes, mas apreendê-los de maneira correta e adequada que pode ser entendida como uma "reconstrução" do conhecimento; de modo que ele venha a constituir parte do seu próprio eu e não como algo justaposto, aceito sem compreensão.

O uso indiscriminado do termo construtivismo pode, por vezes, passar a impressão da impossibilidade do ensino, da transmissão e de que cabe ao estudante "refazer" todo o conhecimento por si mesmo.

A grande contribuição do construtivismo concentra-se, talvez, na questão do método. Propõe novas metodologias para o processo da aprendizagem de modo a que ocorra de modo correto, ou seja, a transmissão do conhecimento de modo que o aluno o compreenda, e o situe adequadamente e seja capaz de utilizá-lo de modo criativo e independente. Em primeiro lugar, objetiva-se a organização do pensamento. Conhece-se algo quando se tem desse objeto uma visão de conjunto e consegue-se situar suas partes de maneira ordenada.

Algumas noções aparecem como fundamentais nesse processo: as noções de espaço e tempo, as de causa e efeito, a de encadeamento lógico que permitem distinguir o princípio, o desenvolvimento e a conclusão. Torna-se, portanto, uma exigência da análise dessa teoria, o estabelecimento de referenciais de avaliação do conhecimento "construído". 
A avaliação do conhecimento construído deve considerar a criatividade e a autonomia do sujeito não se limitando a verificar o êxito de condicionamentos. $O$ objeto da avaliação passa a ser não exatamente o conteúdo do saber, mas, o modo pelo qual foi aprendido.

Do entendimento do termo nesse sentido, fatalmente vai ocorrer a "construção" do conhecimento. Seja o conteúdo transmitido pelo professor ou descoberto pelo aprendiz, vai ele sempre ser organizado e estruturado de modo pessoal e peculiar. Os processos de assimilação e de acomodação são pessoais e intransferíveis embora não totalmente diferentes em cada um.

Graças à intencionalidade como bem mostrou Husserl (1980), o sujeito vai interferir no objeto do conhecimento construindo-o a seu modo. A rigor, é impossível o conhecimento passivo, puramente receptivo. Todo conhecimento resulta em última análise de uma construção do sujeito sobre o seu objeto.

A discussão desloca-se da epistemologia para a metodologia de ensino. Sobre o melhor método para levar o aluno a aprender o objeto de conhecimento. Sobre como promover uma aprendizagem que não cerceie a criatividade, mas, ao contrário, a estimule e desenvolva e, ao mesmo tempo, não a conduza ao solipsismo e a incomunicabilidade.

Algumas contribuições positivas do Construtivismo seriam:

- uma maior consideração pelo nível de desenvolvimento do aluno;

- maior preocupação com a compreensão do conteúdo ensinado;

- maior consciência da importância dos aspectos afetivos da aprendizagem;

- maior atenção ao interesse como motivador da atenção, fator preponderante para a aprendizagem.

\section{A NOÇÃO DE CONHECIMENTO}

O conhecimento resulta da interação do sujeito com o objeto. O desenvolvimento cognitivo ocorre pela assimilação intelectual ou sensível do objeto do conhecimento a estruturas próprias e existentes no sujeito e pela acomodação dessas estruturas ao objeto da assimilação.

O conhecimento pode dar-se em nível empírico, científico, filosófico ou por fé.

A tão comentada passividade a que a criança estava condenada pela escola tradicional parece impossível já que o processo da aprendizagem, segundo os pressupostos do construtivismo exige a ação não como movimento externo, mas como intencionalidade, como movimento 
intelectual de busca e apreensão. Assim, ou ocorre a atividade intencional por parte do aprendiz, ou não ocorre a aprendizagem. Assim sendo, pode-se admitir que é a pessoa que sempre, com qualquer metodologia de ensino, desde que haja a apreensão do conteúdo, “constrói” o seu próprio conhecimento.

Relacionando-se a ideia de construção de conhecimento à didática aos métodos de ensino, chega-se à importância da ligação dos estudos de psicologia nas suas diversas especificidades com a constituição dos currículos.

Há a necessidade inicial do estabelecimento de critérios pedagogicamente justificáveis para a seleção dos conteúdos programados para cada etapa do desenvolvimento. Para que se perceba o conhecimento construído é necessária a avaliação do progresso do educando comparando-o com ele próprio em avaliações anteriores.

\section{A INTERPRETAÇÃO DA FENOMENOLOGIA}

Tratando-se de construção do conhecimento, pode-se dizer que o método fenomenológico pode ser de grande ajuda já que propõe a distinção entre o conhecimento ingênuo e o conhecimento do "eidós", da essência do fenômeno. Propõe como etapas da pesquisa, ou seja, da "construção" do conhecimento, pode-se dizer, a descrição da realidade, a interpretação dos dados constatados, a projeção das consequências e possibilidades.

A Fenomenologia poderia então ser entendida como meio de conhecimento para o homem comum e não apenas como método para o cientista. Quando Husserl (1970 p. 83) afirma que "a fenomenologia procede elucidando por uma visão, determinando o sentido e distinguindo o sentido.", quando diz que "ela compara, distingue, estabelece ligações, relaciona, divide em partes ou isola momentos, mas isso no quadro de uma pura visão" visa à obtenção de um método adequado para o conhecimento em geral.

Por meio do método fenomenológico, por-se-iam a descoberta os elementos menos aparentes dos fenômenos que constituem o que tem o ser de mais fundamental: poder-se-ia relacionar essa busca com o processo da educação considerando-a como o aprendizado da busca do valor, da busca do essencial e assim da construção do próprio conhecimento. Pode-se dizer que a própria postura da fenomenologia já implica um olhar pedagógico embora nenhum dos grandes autores dessa corrente de pensamento tenha redigido uma Filosofia da Educação propriamente dita. 
A fenomenologia é fundamentalmente, um método vinculado à filosofia, um método para o conhecimento do fenômeno. Considerando-se o conhecimento como um fenômeno, chega-se a que ele pode ser estudado pelo método da fenomenologia.

Afirma Muniz de Rezende:

O método da fenomenologia não é apenas definitivo das essências. Na verdade, a intuição das essências visada pela fenomenologia, não diz respeito a um mero conteúdo conceitual que possa ser definido, mas à significação de uma essência existencial que como tal deve ser descrita. (REZENDE, 1970, p. 17)

O que se pretende em educação é exatamente a busca e a compreensão da significação; a significação e o sentido da existência ciente de que essa compreensão nunca se fará plenamente.

Buscando novamente o concurso do Prof. Muniz de Rezende encontra-se:

Talvez pudéssemos dizer que o método da fenomenologia é afinal, um método de aprendizagem diretamente relacionado com a experiência cultural e em essência atento ao problema do sentido da existência. Todos nós somos aprendizes em relação a ele, constantemente desafiados a tornarmo-nos mais plenamente sujeitos de nossa história, sujeitos do nosso próprio destino cultural. (REZENDE, 1990, p. 51)

Tanto a temática quanto o método da fenomenologia visam o conhecimento do sentido da existência. Do seu ponto de vista, a educação vai consistir na apreensão do sentido da existência. Para a fenomenologia, a aprendizagem se caracteriza pela compreensão do significado do fenômeno.

Considerando o sujeito como "pessoa", a primeira visada da fenomenologia na busca de sentido é a da sua condição corporal. A compreensão da função dos sentidos e do esquema corporal. Em seguida, procura a compreensão da sua racionalidade. Do funcionamento da inteligência na apreensão da verdade. Como chegar à aprendizagem significativa, como chegar à interpretação do sentido, à crítica do conhecimento, ou seja, à chamada "redução fenomenológica". Continuando com o referencial "pessoa", o olhar da fenomenologia volta-se para a vontade e a sua expressão como liberdade psicológica e como responsabilidade. A busca da compreensão implica na liberdade de ação e na responsabilidade. Finalmente, a postura fenomenológica facilita a vida afetiva ao ter como objetivo o conhecimento da verdade e do sentido da existência.

De acordo com a fenomenologia, o sentido e o ser do fenômeno não podem ser dissociados. Embora os fenômenos se apresentem ao sujeito por intermédio dos sentidos, são eles sempre dotados de um sentido que lhes é doado pela consciência. Cabe ao educador levar o educando à reflexão sobre esse sentido. 
$\mathrm{Na}$ interpretação de A. Dartigues (1973, p. 22), para a fenomenologia, "a intuição da essência se distingue da percepção do fato: ela é a visão do sentido ideal que atribuímos ao fato materialmente percebido e que nos permite identifica-lo." O processo das sucessivas reduções pode ser considerado como solução para esse problema. Em primeiro lugar, deve-se admitir que esse processo possa ser aprendido. É um modo sistemático de se olhar o fenômeno que pode ser "ensinado" ao educando. Aprende-se a deixar de lado o secundário, o acidental para atingir a coisa em si mesma. Essa aprendizagem pode dar lugar a uma nova modalidade de ver, a um hábito que vai fazer com que cada vez mais e melhor se chegue às "coisas nelas mesmas". Assim como as reduções não se fazem de modo absoluto, também não o processo da educação.

O entendimento da fenomenologia como a ciência que visa descrever as essências da consciência e de seus atos dá a justificativa para que ela seja tomada como fundamentação para uma teoria da educação.

Como o ver as coisas "nelas mesmas" Husserl pretende descrever o "aparecer" das coisas não como realidade factual, mas de modo a aprender o seu sentido. Talvez, possa-se considerar ser esse o objetivo primordial da "construção" do conhecimento.

Para o método fenomenológico, o sentido ou intenção significativa vai ser dado pelo ato de significar. A fenomenologia parte da constatação de que as vivências da consciência são vivências intencionais, ou seja, significativas de um objeto. $\mathrm{Na}$ análise fenomenológica da consciência vai ser importante a compreensão de que ela ocorre como vivência intencional, de que ela se refere, se dirige, se volta intencionalmente para um objeto. Sua meta é atingir a essência significativa do objeto, é chegar à intenção significativa. Note-se que a consciência apreende seu objeto de diferentes modos. Manifesta-se aí a importância da educação no processo da aprendizagem.

A consciência construiria seus objetos a partir de uma matéria primitiva formada por associações perceptivas e de hábitos constituídos durante a infância. A relação entre a intuição dos objetos visados e significados e a intuição que permite conhecê-los em si mesmo seria feita pela experiência vivida da consciência. $O$ conhecimento ocorreria, portanto, de modo imediato na consciência pré-reflexiva do nível da vivência. Os tipos de vivência deixariam marcas, modificariam o próprio sujeito não interferindo apenas no conhecimento.

Existiria, portanto, um "eu ingênuo" e outro que compreenderia que saberia ultrapassar as aparências e pelo conhecimento do fenômeno, chegar à apreensão do ser. Essa mudança de enfoque resultaria da educação que não se limitaria a um processo de aculturação, de informação ou de condicionamento, mas atuaria na própria constituição do sujeito. 
Como bem mostram Kelkel e Scherer,

A expressão intuição das essências não implica em nenhuma atitude mística, em nenhum mistério. Não é uma atitude para os iniciados, os chamados filósofos ou santos, mas um posicionamento diante do real possível de ser atingido por qualquer um, ou seja, um estado que pode ser alcançado por uma forma de educação. (KELKEL; SCHERER, 1982, p. 31)

Seguindo Husserl (1980, p. 48), "a razão não é uma faculdade que tenha o caráter de um fato acidental, ela não engloba sob sua noção fatos acidentais, mas é uma forma de estrutura universal e essencial da subjetividade transcendental.".

A fenomenologia ao tomar a intencionalidade como visada da consciência e critério da produção de sentido, vai permitir o estudo dos fenômenos humanos nos seus fundamentos enquanto vividos e promover uma metodologia da compreensão para as ciências humanas, entre elas a Educação. Admitindo-se que deve compreender os artefatos, os objetos inanimados como objetos culturais porque reveladores de intenções, com mais razão devem ser compreendidos os comportamentos que mostram as intenções do sujeito. $\mathrm{O}$ educador parte sempre da possibilidade de conhecimento do "outro" e do prévio conhecimento da situação ideal

Visando à realização plena do homem, a educação deve começar pela compreensão do comportamento como a capacidade de perceber o "outro" do seu interior, do ponto de vista de sua intenção, da sua humanidade.

O método fenomenológico vai de certo modo, "ensinar" a ver além das aparências, a detectar, a decodificar. A desvencilhar dos fatores que interferem no conhecimento, na compreensão do mundo, do outro e de si mesmo para a promoção do autoconhecimento e assim da autodeterminação.

É fundamental o papel da educação já que a análise da consciência que conduz à intuição da essência não pode exercer-se de qualquer maneira, mas da maneira adequada ao aprimoramento da pessoa do sujeito.

Sendo o sentido do mundo dado não por um único sujeito, mas pela pluralidade das consciências, vai ser pelo intercâmbio entre elas que se tornará objetivo como o mundo o qual todos participam.

A constituição do mundo na visão de Husserl não é um fenômeno subjetivo. Há não mais uma subjetividade transcendental, mas uma intersubjetividade transcendental. Essa parece ser uma colocação de especial importância para a educação. 


\section{CONSIDERAÇÕES FINAIS}

Ao término desse estudo, algumas observações podem ser feitas. Primeiramente, percebe-se que o papel da educação na construção do conhecimento depende do conceito de educação utilizado. Sendo inúmeras as conceituações, optou-se nessa reflexão pela que a entende como o processo que leva o educando a reconhecer, buscar, instaurar e hierarquizar os valores de modo a aprimorar-se como "pessoa" e como "personalidade".

Aceitando-se esse referencial, percebe-se que a educação vai situar a "verdade" a exigência de sua constante procura, juntamente com outros valores, no topo da hierarquia. A educação ao valorizar a verdade vai ser determinante para a construção do conhecimento.

A importância dada à busca do conhecimento, à aprendizagem em geral depende, portanto, do escalonamento dos valores proposto pelo processo educacional.

Assim como há os que priorizam o trabalho, o sucesso financeiro, os bens materiais ou outros valores, há os que dão grande valor à instrução como processo de apreensão da bagagem de conhecimentos acumulados pela humanidade e à capacidade de avaliá-los criticamente.

O aprendizado da ciência exige o domínio da metodologia científica, do processo histórico que a explica, dos diferentes estatutos de cientificidade. Cabe às instituições de ensino oferecer o conhecimento dos conteúdos da ciência e preparar os futuros pesquisadores neles instaurando um novo olhar para o real e assim colaborar para a construção da ciência. $O$ ensino não se limita à transmissão de saberes constituídos para serem aceitos, fixados, internalizados, mas, ao contrário, deve-se promover a busca do conhecimento de um modo ativo, uma mudança conceitual que pode ser entendida como uma construção de conhecimento.

O conhecimento intelectual e a capacidade de avaliação do sujeito formam a sua instrução. A modificação que dela decorre, seja nele próprio, seja no meio ambiente físico ou social constitui a cultura. Assim sendo, tanto o padrão de educação, como o da instrução como o da cultura vão facilitar ou dificultar a construção do conhecimento.

Como segunda constatação, nota-se a importância da clara definição da noção de "construção do conhecimento". Numa primeira acepção, o termo pode ser entendido como o labor da comunidade científica. Um procedimento que requer tempo, dedicação, disponibilidade econômica, testagem para validação entre outras exigências.

Outra conceituação da noção de "construção do conhecimento" a entende como o processo individual de apreensão, elaboração e assimilação dos conteúdos dos saberes. 
A escola participa desse processo ao levar o estudante a ser capaz de observar, testar, relacionar, organizar, sistematizar o conhecimento para que o aprenda adequadamente, mas, a "construção" é individual no sentido que cada um vai apreender os conteúdos do conhecimento de modo próprio e pessoal.

Pode-se então entender "construção do conhecimento" como: a) saber produzido pelo filósofo, pelo cientista resultante da reflexão e da pesquisa sistemática: os conteúdos das ciências e dos diferentes saberes das várias áreas do conhecimento. b) construção do conhecimento como o modo pelo qual cada um apreende a informação e aprende algum conteúdo. Nesse sentido, o sujeito não propriamente "constrói" o saber, mas o "constrói" em si mesmo apropriando-se de um conhecimento já estabelecido. Cada sujeito apreende o que the foi transmitido de um modo semelhante, mas não idêntico. É a semelhança que permite a comunicação. Há, como afirma Husserl (1980) uma intersubjetividade entre os que dominam a mesma área do saber o que demonstra na "construção do conhecimento". Essa comunicação intersubjetiva permite o progresso da ciência já que ela não ocorre sempre de modo idêntico e que grupos mais homogêneos melhor se compreendem. Há níveis de conhecimento intersubjetivo de acordo com os diferentes estágios de educação, de instrução e de cultura.

Conclui-se, por fim que qualquer que seja a conceituação aceita para a noção de "construção do conhecimento" o papel da educação é fundamental. 


\section{REFERÊNCIAS}

AULETE, C. Minidicionário contemporâneo da língua portuguesa. Rio de Janeiro: Lexikon, 2009.

COOMBS, P.; AHMED, M. Attacking Rural Poverty: how Non-Formal Education can help. In: GHANEN, E; TRILLA, Y. Educação formal e não formal: pontos e contrapontos. São Paulo: Summus, 2008.

DARTigueS, A. O que é a Fenomenalogia. Trad.: Maria José J. G. de Almeida. Rio de Janeiro: Eldorado, 1973.

GHANEM, E; TRILLA, J. Educação formal e não formal: pontos e contrapontos. In: ARANTES, V. (Org.). São Paulo: Summus, 2008.

HOUAISS, A. Minidicionário da língua portuguesa. Rio de Janeiro: Objetiva, 2004.

HUSSERL, E. L’idée de la Phínoménologie (cinq leçons). Trad.: Alexandre Lowit C. Épimethée. Paris: Press Universitaires de France, 1970.

Méditations Cartesiennes, Troisiéme Méditation. Trad.: Maria Gabrielle Peiffer e Emmanuel Lévinas. Paris: Librairie Philosophique J. Vrin, 1980.

KELKEL, A.; SCHÉRER, R. Husserl. Trad.: Joaquim Coelho Rosa. São Paulo: Edições 70, 1982.

PIAGET, Jean. Epistemologia genética. 2. ed. São Paulo: Martins Fontes, 2002.

Psicologia da inteligência. Rio de Janeiro: Zahar, 1947.

Seis estudos de Psicologia. Rio de Janeiro: Forense Universitário, 1978.

REALE, M. Paradigmas da cultura contemporânea. São Paulo: Saraiva, 1996.

REZENDE, A. Concepção fenomenológica da educação. São Paulo: Cortez Autores Associados, 1990.

SODRÉ, M. Reinventando a Cultura. Petrópolis: Vozes, 2001.

WERNECK, Vera Rudge. Cultura e Valor. Rio de Janeiro: Forense Universitária, 2005. 


\section{RESUMO}

O artigo tem como objetivo refletir sobre o papel da educação na construção do conhecimento. De início aceita como conceituação de educação, o processo que leva o educando a reconhecer, buscar, instaurar e hierarquizar os valores de modo a aprimorar-se como pessoa humana e como personalidade individual. Distingue por isso, educação, instrução e cultura. Em seguida analisa a noção de "construção do conhecimento" mostrando as diferentes compreensões do termo: como produção cient ífica resultante das pesquisas dos especialistas, dos cientistas nas suas diversas áreas e como apreensão individual dos saberes constituídos, ou seja, como aprendizagem individual. Apoia-se na Teoria dos Valores e na Fenomenologia para concluir mostrando a interferência da educação na construção do conhecimento seja como aprendizagem individual pelo reconhecimento e pela hierarquização dos valores.

Palavras-chave: Educação. Construção do conhecimento. Cultura. Fenomenologia.

\section{THE ROLEOF THE EDUCATION IN THE LEARNING AND IN THE KNOWLEDGE}

\section{ABSTRACT}

The aim of the article is to reflect on the role of the education in the elaboration of knowledge. Initially accepted as conceptualization of education, the process that leads the learner to recognize, seek, establish and prioritize values, in order to improve itself as a human person and as an individual personality. For this reason, distinguish itself education, instruction and culture. After that, it is analyzed the notion of "knowledge construction" showing the different understandings of the term: as a scientific production resulting from the research of specialists, scientists in their sundry areas and as individual apprehension of the constituted knowledge, in other words, as individual learning. It is based on the Theory of Values and Phenomenology to conclude, revealing the interference of the education in the construction of the knowledge, as a collective knowledge, or as individual learning through recognition and hierarchy of values.

Keywords: Education. Construction of the knowledge. Culture. Phenomenology.

\section{EL PAPEL DE LA EDUCACIÓN EN EL APRENDIZAJE Y EL CONOCIMIENTO}

\section{RESUMEN}

Este artículo tiene como objetivo reflexionar sobre el papel de la educación en la construcción del conocimiento. En principio se acepta como conceptuación de la educación, el proceso que lleva al educando a reconocer, buscar, instaurar y jerarquizar los valores con el propósito de que mejore como persona humana y como personalidad individual. Distingue así, educación, instrucción y cult ura. Enseguida analiza la noción de "construcción del conocimiento" mostrando las diferentes comprensiones del término: como producción científica resultante de los estudios de los especialistas, de los científicos en sus diversas áreas y como preocupación individual de los conocimientos constituidos, o sea, como aprendizaje individual. Se apoya en la Teoría de los Valores y en la Fenomenología para concluir mostrando la interferencia de la educación en la construcción del conocimiento ya sea como aprendizaje individual por el reconocimiento y por la jerarquización de los valores.

Palabras clave: Educación. Construcción del conocimiento. Cultura. Fenomenología.

Submetido em: 24 de junho de 2018 Aprovado em: 30 de abril de 2019 